\title{
Deficiência visual e performance musical: refletindo sobre os elementos motivadores do projeto Música Transformando Vidas
}

Visual impairment and musical performance: reflecting on the motivating elements of the Music Transforming Lives Project

Paulo Eduardo Mauá Escola Superior de Educação e Ciências Sociais, Instituto Politécnico de Leiria, Portugal pemaua@hotmail.com 


\section{Resumo}

Este estudo baseia-se num relato de experiência e tem como objetivo inferir o que motiva um grupo de pessoas com deficiência visual, leigas em música, a participar de aulas, ensaios e subir no palco frente a uma plateia lotada. Narra a caminhada dos integrantes do projeto Música Transformando Vidas (Promuvi), em mais de uma década de existência, na partilha de momentos de pertença, socialização e desafios, a composição do grupo, a interação dos docentes e alunos, as dificuldades de aprendizado, o repertório utilizado e, principalmente, reflexiona sobre os mecanismos de motivação que fazem com que os integrantes recuperem a autoestima por meio da musicalização.

Palavras-chave: Motivação. Inclusão musical. Performance. Autoestima. Deficiência visual.

\section{Abstract}

This study, based on an experience report, aims to infer what motivates a group of visually impaired people, lay people in music, to participate in classes, rehearsals and go up on stage in front of a crowded audience. It narrates the journey of the members of the Music Transforming Lives Project - Promuvi, in more than a decade of existence, in sharing moments of belonging, socialization and challenges, the composition of the group, the interaction of teachers and students, learning difficulties, repertoire used and mainly reflects on the mechanisms of motivation that make the members regain self-esteem through musicalization.

Keywords: Motivation. Musical inclusion. Performance. Self-steem. Visual impairment.

\footnotetext{
1 Graduação em Engenharia Mecânica pela Escola de Engenharia de São Carlos - USP - Universidade de São Paulo (1985). Pós-graduação em PIGEAD - Planejamento, Implementação e Gestão em Educação à Distância, pela UFF - Universidade Federal Fluminense em 2012. Tutor presencial em Educação Musical da Universidade Federal de São Carlos (2013/2014) e Tutor Virtual da mesma universidade na disciplina de Inclusão Musical, desde 2014. Tem experiência na área de Educação, com ênfase em Educação a Distancia EaD. Mestrado em Comunicação Acessível pela Escola Superior de Educação e Ciências Sociais do Instituto Politécnico de Leiria, Portugal (2015 a 2017) com a dissertação "Ensino de Música para Cegos sem Braile: Desafio ou Loucura?"
} 


\section{Introdução}

Expressões como "Nossa, conseguem tocar mesmo sendo ceguinhos?" e "Nunca pensei que cegos fizessem coreografia durante a música!" são rotineiras aos finais dos concertos do projeto Música Transformando Vidas (Promuvi). Os integrantes do projeto consideram-nas elogiosas ${ }^{2}$, ou seja, com caráter de opinião favorável misturado com espanto e perplexidade. $O$ que é visível aos olhos da plateia é o querer dos músicos em "fazer música" e a partilha ao vivo. Um dos focos das constantes apresentações do grupo é mostrar que pessoas com deficiência podem realizar atividades musicais e expressar-se livremente. Além da diversão, o permanente cultivo da autoestima individual acaba demonstrando a conquista de um espaço da cidadania do grupo, fruto de um aprendizado espontâneo e interessante.

Segundo Schlichting (2016), a motivação só acontece se o integrante de um determinado projeto se interessar em estudar o instrumento de forma regular e de maneira genuína. A motivação para o estudo musical precisa vir de dentro para fora. Caso contrário, será forçado e não ocorrerá o aprendizado. Hallam (2002) relata que os fenômenos motivacionais estão relacionados a uma rede complexa entre as características pessoais e o ambiente que envolve o sujeito, por isso é importante que o educador e os integrantes do projeto compreendam como provocar seus pares para a obtenção dos resultados desejados.

A tarefa de motivar o integrante do projeto a aprender um instrumento musical e conquistar a confiança para que se apresente em público está diretamente relacionada à objetivação de metas pessoais e de grupo. Hallam (2002) nos conduz por teorias da motivação para explicar o que leva o homem a perseguir metas baseadas em pontos de vista, tendências, históricos, personalidade, incluindo o ambiente econômico, social e cultural de cada um. Tudo pode influenciar o aprendizado musical, principalmente no que diz respeito a uma pessoa com deficiência visual.

A performance ao vivo é o ápice da entrega e aquisição de conhecimento do integrante do projeto. Lima (2006) define performance a partir da raiz latina do verbo formare: dar forma, fazer, criar. "O prefixo per serve para reforçar o conteúdo semântico dos adjetivos, verbos e derivados" (LIMA, 2006, p.12). Com isso, performance é muito mais que fazer ou dar forma. "Observamos que a ausência da partitura na música antiga funde as figuras do compositor, intérprete e ouvinte" (LIMA, 2006, p.48). Para os cegos do projeto, a partitura física tradicional não existe como referência. Desconhecem o braile e, por consequência, a musicografia braile. Conservam apenas a imagem musical da peça formada. Dessa maneira, a música é tratada como um evento ritualístico no projeto Música Transformando Vidas, devido à ausência da notação musical, como observa Lima (2006).

2 Elogioso(a): adjetivo que contém elogio ou que é do caráter do elogio. Fonte: Dicionário Priberam. Disponível em: https://dicionario.priberam. org/elogioso. Acesso em: 3 ago. 2020. 


\section{Desenvolvimento: a motivação para os concertos}

Segundo Freire e Tavares (2011), a autoestima é identificada como uma das características mais associadas aos indivíduos com altos níveis de felicidade e que atingem um sentimento de autorrealização e de bem-estar psicológico. As autoras ainda definem autoestima como avaliação afetiva do "valor, apreço ou importância que cada um faz de si próprio" (FREIRE; TAVARES, 2011, p.185).

Dentro do projeto Música Transformando Vidas, constatam-se:

$\checkmark$ a relação da performance musical com a autoestima;

$\checkmark$ a importância da variedade do repertório;

$\checkmark$ o fator memória musical dos integrantes com deficiência visual e a relação da memorização com os diversos gêneros musicais com a performance;

$\checkmark$ a execução musical e os aspectos musicais dos concertos.

Para Hallam (2002), três aspectos principais são a chave da motivação no aprendizado: valor, expectativa e afeto. No componente de valor, trabalha-se com a crença de que o integrante do projeto tem consciência sobre a importância e o valor da tarefa a ser executada. Em termos de expectativa, o aluno precisa acreditar no componente afetivo e que pode realizar a tarefa. O projeto trabalha o sentimento sobre si próprio e as reações à tarefa realizada em aulas e concertos. Segundo Lima (2006), a execução musical valoriza e realça o aprendizado e exige do intérprete atuações pré-estudadas e avaliadas que legitimarão a performance.

Lima (2006) lembra que a palavra performance é utilizada com um significado similar ao das palavras interpretação, execução e prática, e que as três palavras possuem sentidos diferentes em sua origem e formação. Performance pode significar o resultado obtido em uma exibição em público, a ação de desempenhar determinado papel ou manifestação artística que pode combinar várias formas de expressão ${ }^{3}$. Outra definição de performance é como forma de arte que combina elementos do teatro, das artes visuais e da música sem a participação do público, de modo geral. No caso do Promuvi, muitas vezes a plateia interage com o grupo, transformando a apresentação em happening ${ }^{4}$.

A preocupação em dar visibilidade ao projeto Música Transformando Vidas está relacionada com a definição de Milhano (2012) sobre gerar atividades que causem impactos na reabilitação cognitiva e motora das pessoas acima de cinquenta anos, que é o caso dos integrantes do Promuvi. Com as apresentações e ensaios, os músicos acabam sendo estimulados em suas funções cognitivas, emocionais, sociais e sensoriais. O estímulo promove o aumento da autoestima, pois observamos nesse relato de experiência que os membros passam a se valorizar mais.

A performance pública é a oportunidade de participar de desafios que permitam o desenvolvimento físico e mental e a socialização das pessoas envolvidas. Milhano (2012) destaca que o gosto pela música (musicofilia) faz com que possamos detectar notas

3 Fonte: https://dicionario.priberam.org/performance. Acesso em: 10 ago. 2020.

4 Fonte: http://enciclopedia.itaucultural.org.br/termo3646/performance. Acesso em: 5 ago. 2020. 
erradas, descobrir músicas de que gostamos e recordar melodias da memória musical que temos.

\section{Experiências auditivas: uma jornada sem fim}

$\mathrm{Na}$ produção musical com adultos e, principalmente, na maturidade de pessoas com deficiência, a exigência exagerada pode desmotivar o indivíduo ou o grupo. Luz (2008) enfatiza a necessidade de constante atenção na análise e avaliação dos integrantes de determinado grupo musical e de estar atentos como mediadores e responsáveis pelos resultados conquistados pelos envolvidos. A motivação tem papel especial na aprendizagem musical, pois, além de proporcionar o incentivo para determinar o início de uma nova experiência de vida, é também ela que mantém o vínculo necessário para que o aluno continue a frequentar as aulas e estudar em casa.

A aquisição de novas competências pode ser estimulante, mas a dosagem das competências precisa ser avaliada de forma particular. Cada aluno demanda um processo de investigação-ação, com muita atenção, moderação e análise dos resultados e da satisfação do envolvido. Por isso, para elevar a eficiência dos envolvidos, o feedback apropriado e cuidadoso precisa ser constante não só quando os alunos são bem-sucedidos, mas também quando erram. Quando falham, as críticas precisam ser construtivas para que os alunos entendam o que precisa ser mudado e como realizar as mudanças sem constrangimentos.

Como uma das estratégias para minimizar o impacto da deficiência visual no processo de utilização do som como ferramenta de socialização, Miller e Ockelford (2005) sugerem a exposição de pessoas com deficiência visual ao maior número possível de experiências auditivas. Os professores precisam equilibrar "o que ensinar" com "o que conseguem aprender" os alunos por meio de atividades musicais passíveis de serem executadas. Com isso, as pessoas com deficiência poderão atingir o que Cardoso (2007) chama de "estado de fluxo", conceito proposto pelo psicólogo Mihay Csikszentmihalyi $(1990)^{5}$ e que ocorre quando os sujeitos conseguem um equilíbrio entre a própria capacidade de acreditar que conseguem resolver determinada tarefa e o grau do desafio apresentado. Este tipo de experiência tem profundo impacto emocional e ajuda no desenvolvimento pessoal.

Tocar com e para outras pessoas está ligado diretamente ao processo de aprendizado. Os encontros musicais são ricas experiências, e as aulas de prática de conjunto/ orquestra abertas ao público transformam-se em ensaios pulsantes do repertório, sempre em renovação. Com isso, o grupo está sempre pronto para os concertos e chega a realizar trinta concertos ao ano em residenciais de idosos, creches, escolas públicas e particulares, universidades, teatros, praças e até cemitérios.

5 Disponivel em: https://www.arataacademy.com/port/coaching/mihaly-csikszentmihalyi-estado-de-flow-fluxo-como-elemento-de-realizacao-e-alta-performance/. Acesso em: 27 nov. 2020. 


\section{Características do projeto e dos músicos}

O projeto Música Transformando Vidas (Promuvi) foi criado em 2009 com a intenção de gerar agentes multiplicadores em entidades carentes da região da Baixada Santista, no estado de São Paulo, Brasil. Com o advento da primeira pessoa cega no grupo, a partir de 2010 foram formadas novas turmas apenas com pessoas cegas ou de baixa visão. As aulas semanais (inicialmente presenciais e agora remotas, devido à pandemia de Covid-19) são de Prática de Conjunto (orquestra) e outros instrumentos musicais. As aulas presenciais são realizadas em espaço disponibilizado pela Casa da Visão, na cidade de Santos (SP), e com apoio financeiro de pessoas físicas e jurídicas, incluindo o Rotary Santos Oeste, onde o projeto nasceu.

Hoje o Música Transformando Vidas possui registro próprio e desde janeiro de 2019 é considerado Utilidade Pública Municipal pela cidade de Santos. As aulas são gratuitas, e a aula de Prática de Conjunto concentra os ensaios semanais para os concertos realizados ao longo do ano. A coordenação é realizada pelo regente da orquestra e autor deste artigo, Paulo Eduardo Mauá, mestre em Comunicação Acessível pelo Instituto Politécnico de Leira, em Portugal, formado pelo Conservatório Musical Dom Pedro I, em Santos, e com registro na Ordem dos Músicos do Brasil. O grupo de alunos do Promuvi é composto em sua maioria por adultos com cegueira ou baixa visão adquirida que chegam ao projeto leigos em música, sem conhecimento teórico ou prático musical.

O projeto conta também com docentes remunerados para as aulas de instrumentos musicais (flauta doce soprano, violão, ukulele, percussão, clarinete, teclado, escaleta, canto coral), sendo um deles (o professor de flauta doce) com cegueira total adquirida. Além disso, o projeto conta com voluntários que não possuem deficiência visual, mas têm interesse em inclusão e na participação de crianças e jovens em situação de vulnerabilidade social. Hoje o Promuvi conta com cerca de quarenta alunos ativos em diversas atividades de educação musical.

\section{Formas de aprendizagem: solfejo e memorização}

Segundo Willems (2009), o solfejo pode ser escolhido como fim pedagógico para aplicações e explorações de ritmo, audição, escalas, intervalos musicais e sequência das notas de determinados trechos melódicos. No Promuvi, o solfejo foi a maneira encontrada para que os alunos registrassem "mentalmente" as frases melódicas, memorizando-as, e por consequência possibilitassem a digitação da sequência das notas na flauta doce soprano, instrumento utilizado pelos iniciantes leigos em música que chegam ao projeto.

Ainda seguindo a metodologia de Willems (2009), os trechos trabalhados não precisam ser metricamente cronometrados ou semelhantes entre si, mas proporcionar exercícios de diferentes memórias com interferência recíproca. Com isso, é costume exercitar em sala de aula o solfejo de naipes de instrumentos diferentes antes da execução final da música por meio da prática de conjunto. Com o propósito de refinar a apreciação musical, os alunos assistem regularmente a apresentações de outras orquestras, 
e, depois do espetáculo, o grupo discute o repertório, os arranjos e a performance.

O aprendizado dos integrantes do Promuvi tem como base também alguns aspectos da filosofia Suzuki ${ }^{6}$. Fonterrada (2008) descreve os princípios básicos da aprendizagem do método Suzuki, voltado especificamente para crianças, mas que pode ser facilmente adaptado para a musicalização de adultos com deficiência visual:

$\checkmark$ repetição constante (técnica utilizada no solfejo para a memorização de determinado trecho musical e da música por inteiro);

$\checkmark$ formação do repertório (amplo e diversificado);

$\checkmark$ estímulo à habilidade de memória e, principalmente;

$\checkmark$ estímulo à execução "de ouvido" (fator predominante dos músicos com deficiência visual sem conhecimento e possibilidade de leitura da partitura com a musicografia braile).

Vale uma observação importante: mediante a vivência dos músicos, a terminologia mais adequada a ser utilizada é "tocar por ouvido" e não "tocar de ouvido".

\section{Relato de experiência}

Para saber se os concertos são de valia para o grupo, resolvemos fazer uma investigação que resultasse em um relato de experiência do grupo. A população-alvo e amostra do interesse da pesquisa foram os integrantes do projeto Música Transformando Vidas (Promuvi), pessoas com deficiência visual, parcial ou total, ou videntes (normovisuais). Alguns dados essenciais para o desenrolar da entrevista foram coletados: idade, escolaridade, sexo, local de residência, rendimento familiar, tipo de deficiência, origem da deficiência, tempo de vida dentro do projeto etc.

A partir das informações levantadas, elaboramos uma entrevista estruturada oral como instrumento de coleta de dados para um maior controle sobre o conteúdo por parte do investigador, sem preparação particular dos envolvidos, mas com diretrizes claras para os entrevistados: "Traçar o perfil dos integrantes do projeto Música Transformando Vidas (Promuvi) a partir de conhecimentos em braile, instrumentos musicais e motivação para aulas e concerto". A coleta de dados foi realizada ao longo do primeiro semestre de 2019, durante os meses de março, abril e maio. Para os integrantes ausentes durante a entrevista, foram enviados questionários pela internet (e-mail e WhatsApp). As respostas foram preenchidas digitalmente ou respondidas verbalmente em arquivos de áudio e devolvidas para a origem, pelos próprios sujeitos, sem assistência.

Os dados coletados em sala de aula foram registrados durante o desenrolar da entrevista em planilha pré-elaborada com as questões e as respostas transcritas. A análise dos dados consistiu "essencialmente em proceder a uma análise de conteúdo" (FORTIN, 2009, p.249).

A opção por um questionário estruturado tem a intenção de "limitar o sujeito às questões formuladas, sem que ele tenha a possibilidade de as alterar ou de precisar o 
seu pensamento" (FORTIN, 2009, p.249).

As questões fechadas ou de escolha fixa apresentadas durante a entrevista possuíam as seguintes características:

$\checkmark$ respostas dicotômicas (o sujeito respondia SIM ou NÃO);

$\checkmark$ respostas de múltipla escolha;

$\checkmark$ resposta de graduação.

Procuramos trabalhar com graduação de intensidade nas respostas e opções fixas, cercando as possibilidades de significado representativo para a investigação e optamos por respostas exclusivas, em ordem lógica e curtas.

As perguntas formuladas durante as aulas de prática de conjunto foram as seguintes:

$\checkmark$ Qual é o nível do conhecimento de braile?

- Respostas disponíveis: nenhum / iniciante / usuário habitual.

$\checkmark$ Qual é o nível do conhecimento de musicografia braile?

- Respostas disponíveis: nenhum / iniciante / usuário habitual.

$\checkmark$ Qual é o atual conhecimento de instrumento musical?

- Respostas disponíveis: apenas um instrumento musical / dois instrumentos / mais de dois instrumentos.

$\checkmark$ Qual a frequência de estudo do instrumento musical em casa?

- Respostas disponíveis: nenhuma (nunca estuda) / estuda uma vez por semana / duas ou três vezes por semana / diariamente.

$\checkmark$ Considera a presença em aula de prática de conjunto essencial para a performance pessoal em concertos?

- Respostas disponíveis: sim / não.

Com a coleta das informações, tivemos um espelho de como o grupo se comporta em termos de conhecimentos sobre dispositivos de apoio (linguagem braile e musicografia braile) e do instrumento musical.

O presente artigo está focado nas questões apresentadas a seguir durante a entrevista coletiva dos integrantes do projeto com duas questões dicotômicas e a última questão com resposta livre:

$\checkmark$ Você tem motivação para se apresentar em público (concertos)?

$\checkmark$ Você se sente motivado a participar dos concertos ou é indiferente?

$\checkmark$ O que o concerto representa para você?

Para o primeiro questionamento, as respostas disponíveis eram SIM ou NÃO. Já perante a segunda questão, os integrantes tiveram liberdade de se expressar, e as respostas foram gravadas e transcritas a posteriori. As entrevistas presencial e via internet para quem não estava presente nos dias de aula de orquestra tiveram o "objetivo de colher dados relativos às questões de investigação formulada" (FORTIN, 2009, p.245). 


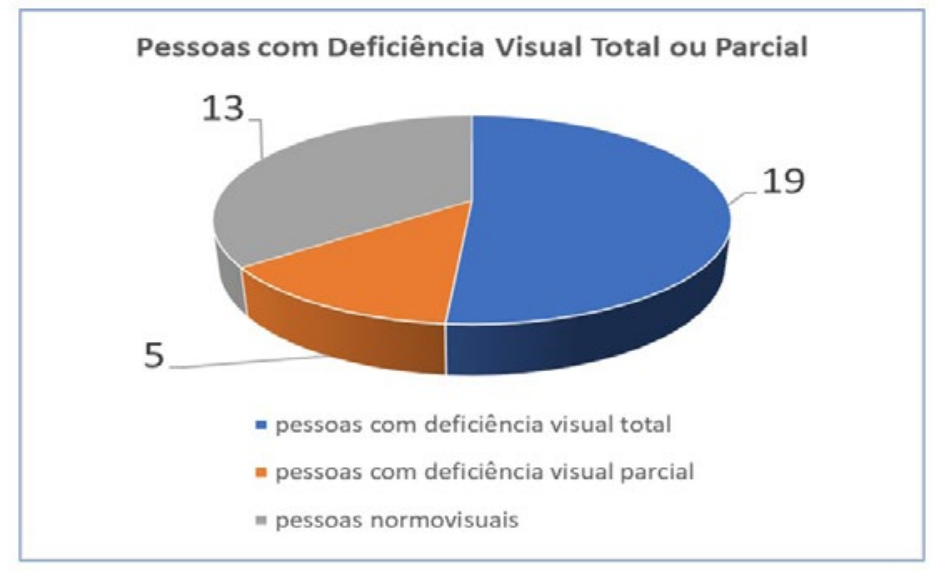

Figura 1 - Gráfico com distinção entre deficiências visuais

Foram entrevistadas 37 (trinta e sete) pessoas (vide gráfico da Fig. 1), sendo 5 (cinco) com baixa visão (deficiência visual parcial), 19 (dezenove) com cegueira (deficiência visual total) e 13 (treze) sem deficiência visual (pessoas normovisuais ou videntes).

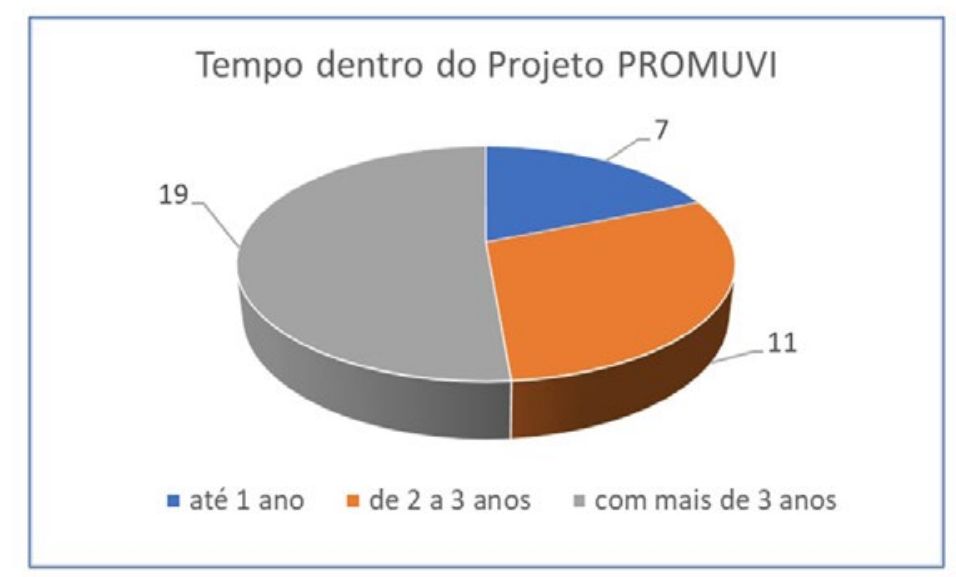

Figura 2 - Tempo de Vida dentro do Projeto

O gráfico em pizza da Fig. 2 ilustra o tempo de permanência dos músicos dentro do projeto. Dos entrevistados, 7 (sete) foram considerados iniciantes (com menos de um ano de aulas no Promuvi), 11 (onze) com tempo de até três anos de convivência de inclusão musical e 19 (dezenove), a grande maioria, com mais de três anos de aulas, ensaios e concertos. 


\section{Resultados obtidos sobre motivação}

Ao perguntarmos aos entrevistados se eles se sentiam motivados a participar dos concertos ou se eram indiferentes, a maior parte do grupo entrevistado mostrou-se motivado com os concertos, e as respostas foram coletadas durante os meses de investigação.

Do grupo entrevistado de 37 (trinta e sete) pessoas, apenas três não souberam responder o que sentiam em relação aos concertos, o que corresponde a apenas $8,11 \%$ dos entrevistados. A maioria (91,89\% dos músicos, com deficiência ou não) mostrou-se motivada em participar dos concertos.

As respostas mais relevantes estão relatadas abaixo:

1 "Proporciona nosso acesso a teatros e novos lugares para concerto, além de compartilhar alegria com quem nos assiste";

2 "Ganho segurança, maturidade, experiência e história para contar";

3 "Quando assisti a primeira vez, quando ainda não fazia parte do grupo, tive uma experiência e tocando tive outra: fazer as pessoas felizes";

4 "Existe um vácuo entre a sociedade e a deficiência, e os concertos vão ao encontro do nome do projeto de poder transformar vidas";

5 "Muito importante para minha vida, dos meus familiares e amigos";

6 "Ajuda-nos a buscar metas, divulgar o projeto e conquistar novos alunos e apoiadores";

7 "Desperta a curiosidade da plateia, com ou sem deficiência, e da mídia";

8 "Considero os concertos realizados em residenciais para idosos ou os didáticos para as crianças os mais emocionantes";

9 "O concerto é fundamental para incentivar novas pessoas interessadas em entrar no grupo para recuperar a autoestima";

10 "A função do projeto Música Transformando Vidas é esse mesmo: ir para a rua, tornar-se visivel";

11 "Acho necessário e gosto muito dos concertos, porque é importante termos a vivência de palco e mostrar à sociedade nosso lindo trabalho, sem contar as experiências que trocamos nos momentos de preparação para apresentação";

12 "Temos a oportunidade de mostrar tudo o que aprendemos durante as aulas e que vamos além de tudo que se diz ser barreira; além disso, podemos mostrar nosso dom musical ao público";

13 "Amo tocar. É emoção à flor da pele. Cada nota é um sentir para o projeto e um presente para quem assiste. Tocar renova a alma e os próprios músicos. Tenho para mim que tocar música é além do falar; é sentir-se vivo. Tecnicamente o concerto é a avaliação do estudar. E com isso conseguimos melhorar cada dia mais".

Do grupo entrevistado, 4 (quatro) alunos não estavam presentes e responderam a posteriori pela internet por meio do aplicativo WhatsApp, seja em texto ou áudio, o que resultou em respostas mais extensas e ricas em detalhes (vide respostas 11, 12 e 13). Dessa maneira, foram obtidas respostas de todos os envolvidos. As respostas listadas justificam e ratificam a existência, as experimentações musicais de inclusão, a expan- 
são para novos instrumentos musicais e a inclusão de pessoas com outras deficiências, além da visual, no projeto Música Transformando Vidas.

Vale a pena lembrar que Sacks (2007) salienta que a música nos ajuda a obter organização ou sincronia quando estamos trabalhando ou nos divertindo. O autor acrescenta que a música tem imenso potencial terapêutico: "A música, para a maioria de nós, é uma parte significativa e em geral agradável da vida. Não falo só da música externa, a que ouvimos com nossos ouvidos, mas também da música interna, a que toca na nossa cabeça" (SACKS, 2007, p.42). Ao descrever a expressão "imagens mentais musicais", Sacks (2007) cita o compositor alemão Ludwig van Beethoven, que continuou compondo mesmo depois de se tornar uma pessoa com deficiência auditiva.

É possível, inclusive, que suas imagens mentais musicais tenham se intensificado com a surdez, pois, com a remoção das entradas de informações auditivas normais, o córtex auditivo pode tornar-se hipersensível, com intensificação da capacidade de formar imagens mentais musicais (e às vezes até com alucinações auditivas). (SACKS, 2007, p.43).

As imagens musicais dos integrantes com deficiência visual do projeto alavancam a motivação para a aprendizagem musical e o melhor desempenho nas performances públicas, tornando os sonhos de uma vida plausível, resultando em uma sociedade mais justa em termos de acessibilidade e inclusão.
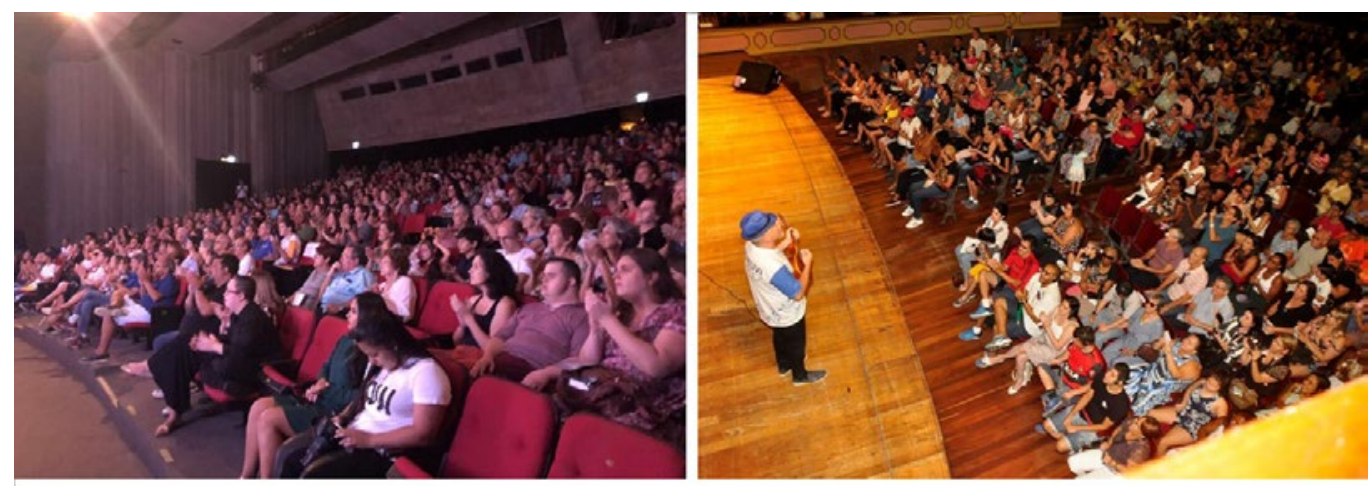

\section{Plateia dos Concertos com Acessibilidade do} PROMUVI

Figura 3 - Teatro Municipal em 2019 (esq) e Teatro Colyseu (dir) em 2018, Santos - SP

Em termos de resultados efetivos, o Promuvi atrai uma grande plateia, principalmente nos concertos com acessibilidade, que contam com a presença de intérprete de língua de sinais (Libras), programa impresso em braile e audiodescrição (Fig. 3).

\section{Reflexões}

A escolha de repertório e interpretação nos concertos foi analisada com os integrantes do projeto como forma de checar não apenas seu papel na motivação do gru- 
po, mas se existia desmotivação ou mesmo evasão de alunos.

Durante uma semana e por meio de contato telefônico, consultamos os alunos ausentes e afastados do projeto com os seguintes questionamentos:

$\checkmark \quad$ O afastamento atual do projeto de música para pessoas com deficiência visual é temporário ou não temporário?

$\checkmark$ Qual a principal (ou principais) causa(s) do afastamento do projeto?

Na primeira pergunta, o termo "não temporário" foi utilizado para não passar ao entrevistado a sensação de que a decisão tomada, espontânea ou involuntariamente, não era considerada definitiva para os demais membros do projeto e deixando claro que o grupo estaria sempre de braços abertos para os integrantes. Os contatos realizados com os alunos que se ausentam por mais de duas semanas consecutivas nas aulas procuram enfatizar a "saudade da pessoa (do ser humano)", e não a "cobrança pela falta na sala de aula". Toda a coordenação e o corpo docente do projeto são orientados a motivar os alunos a retornarem sempre que for possível e o mais rápido que puderem.

Quanto ao segundo questionamento sobre a causa do afastamento, $14,29 \%$ dos entrevistados responderam que era devido a problemas de saúde que provocaram dificuldades de deslocamento e até mesmo a interrupção do estudo regular do instrumento musical. Como o grupo é composto, em sua maioria, de pessoas com cegueira adquirida decorrente de outros problemas médicos, é comum o aluno do projeto se ausentar ao longo do ano devido a complicações de saúde. O mesmo percentual foi encontrado para "problema com transporte público" (14,29\%) e "por preguiça" (14,29\%).

Para as respostas encontradas para as situações de "dependência de terceiros" e "devido ao trabalho" temos $28,57 \%$ em cada uma das opções, totalizando assim $100 \%$ das pessoas entrevistadas. Logo após as respostas recebidas por telefone, uma terceira pergunta era formulada, já em descontraída conversa entre os interlocutores:

$\checkmark$ Em algum momento o afastamento do projeto pode ter sido ocasionado por:

- excesso de exigência teórica nas aulas de música;

- excesso de exigência prática nas aulas de música;

- despreparo do corpo docente;

- tratamento inadequado do corpo docente;

- problemas de sociabilidade com outros alunos;

- amplitude dos gêneros musicais do repertório em estudo;

- outras respostas.

Os entrevistados não escolheram nenhuma das opções acima, principalmente no que se referia ao repertório como alavanca de desmotivação para continuar na orquestra. O último questionamento foi em relação aos concertos e às performances do grupo, como possível motivo de afastamento do projeto. Nenhum dos afastados se declarou desmotivado em relação às interpretações musicais rotineiras do grupo, seja em termos de arranjos musicais ou de constância em subir aos palcos.

As peças musicais trabalhadas no âmbito do Promuvi têm como finalidade incentivar a plateia e motivar os músicos a se redescobrirem na perseverante tarefa de aprender e estudar música. A vitória gradual conquistada a cada música apresentada no decorrer do concerto está relacionada ao controle da ansiedade na performance, 
bem como à necessidade que todos temos de manter a autoestima alta, como ressalta Hallam (2002). Os alunos querem tocar bem, e os professores desejam ver o bom desempenho no palco, assim como a acolhida da plateia. Neste contexto, vêm à tona os aspectos motivacionais presentes em vários níveis, intrínsecos e extrínsecos, como destaca Schlichting (2016).

O momento do concerto expõe o nível da prática de tudo o que foi estudado, bem como a estrutura emocional e psicológica dos músicos. Lima $(2006$, p. 12) reforça ainda que a interpretação musical pressupõe, por parte do autor executante, a "escolha das possibilidades musicais contidas nos limites formais do texto e a avaliação dessas possibilidades". Segundo esta autora, a performance musical transcende a função tecnicista da prática musical e, para um pesquisador atento, faz emergir complexas relações conceituais.

A performance pensada como arte de interpretar exige um pesquisador mais afeto às questões da interpretação propriamente dita, com todos os seus questionamentos filosóficos, psicológicos, históricos e socioculturais; e tem na hermenêutica um método de investigação eficaz para a compreensão dos procedimentos interpretativos musicais. (LIMA, 2006, p.20).

A hermenêutica, quando utilizada na interpretação musical, traz para a performance algo que a linguagem verbal e a ciência não podem explicar, mas que claramente é uma manifestação da expressão humana (LIMA, 2006), como é o caso dos concertos do Promuvi. A ideia de músicos de diferentes níveis misturados e socializados, seja em aula, seja, principalmente, nas performances públicas, beneficia o próprio grupo, conforme foi possivel constatar nas respostas ao questionário. Lopes (2014) destaca que a nova posição da musicologia perante a interpretação musical visa especialmente a

[...] um equilíbrio dentro da investigação musicológica tradicional (aspectos históricos e de teoria), para parâmetros mais próximos da experiência musical - visando assim uma postura mais inclusiva, incorporando perspectivas metodológicas de largo espectro. (LOPES, 2014, p. 1).

O posicionamento de Lopes (2014) é de que a interpretação musical agrega mecanismos facilitadores da integração de várias narrativas e perspectivas metodológicas. "Para uma conceptualização verdadeiramente inclusiva da interpretação musical, teremos que considerar um alargado conjunto de parâmetros" (LOPES, 2014, p. 4), alguns dois quais o autor elenca:

$\checkmark$ a composição original escrita e/ou registrada;

$\checkmark$ o(s) ou a(s) intérprete(s) da melodia;

$\checkmark$ a teoria compreendida pela peça musical;

$\checkmark$ a sociologia envolvida;

$\checkmark$ a recepção da plateia (ou da pessoa);

$\checkmark$ a história (de quem compôs, de quem executa e o tempo histórico em que foi executada);

$\checkmark$ a organologia (os instrumentos musicais envolvidos). 
Todos estes parâmetros interagem dinamicamente e em diferentes proporções para produzir o instante de apreciação musical. A principal dificuldade está em como abordar ontologicamente este todo ou a soma das suas partes, sendo algumas delas mais quantificáveis que outras. "A interpretação musical não é somente a soma das partes integrantes ou investigação derivada de cada parâmetro, mas, como defende Aristóteles em Metafísica, é algo mais do que uma aritmética simples" (LOPES, 2014, p. 4-5).

Além disso, a interpretação está diretamente associada ao prazer de tocar e há de se considerar o tocar em público como forte fator na balança do resultado emocional, para o "bem" ou para o "mal". Nem todos têm o mesmo grau de resposta em termos de percepções, emoções e experiências. Para Hallam (2002), os concertos criam oportunidades para recompensas sociais que incluem a atenção da plateia, o fato de serem o centro de atenção, o gosto de estarem socializando em grupo e o prazer de tocar com primor, ou seja, de realizar plenamente uma tarefa desafiadora.

No início do projeto, em 2009, várias pessoas com deficiência visual recusavam apresentar-se em público. Participavam das aulas, estudavam as melodias, mas se negavam a subir ao palco, mesmo para plateias pequenas e restritas. Com o passar do tempo, o medo deu lugar à necessidade de se descobrir, vencer a timidez e partilhar o momento especial do concerto em grupo. Vale a pena destacar que os alunos estudam mais quando se aproxima a data dos concertos, e, com isso, as performances públicas promovem resultados positivos relacionados à aprendizagem, em termos de motivação pessoal individual e coletiva.

Um dos objetivos do projeto é sensibilizar os professores para que possam ajudar os alunos a transferirem as motivações da aprendizagem musical para outras áreas, para que possam partilhar, para si e com os outros, a aquisição e desenvolvimento de experiências de vida. Com isso, encontram soluções de acessibilidade e rompem barreiras sociais.

\section{Considerações finais}

Como relato de experiência do projeto Música Transformando Vidas, projeto existente desde 2009, é possível definir algumas práticas motivacionais que podem ser aplicadas em grupos musicais com pessoas com deficiência:

$\checkmark$ Trabalhe em grupo. Evite aulas individuais. As pessoas com deficiência já vivem sozinhas e precisam socializar com outras pessoas com deficiência ou não.

$\checkmark \quad$ Procure mesclar o grupo com pessoas com e sem deficiência visual e com níveis diferentes de conhecimento musical. A equalização ocorrerá de maneira natural e é fundamental para o crescimento e respeito do grupo. A partilha de experiências é benéfica, e o resultado da massa sonora é gratificante.

$\checkmark \quad$ Não estimule competições ou prêmios individuais. Não trabalhe com avaliações comparativas. Evite motivadores extrínsecos.

$\checkmark$ Respeite a individualidade e o ritmo de cada um.

$\checkmark$ Seja claro nas explicações e admita os erros cometidos, os seus e os dos integrantes do grupo. Todo erro deve ser encarado como uma experiência a ser aprendida 
e compartilhada.

$\checkmark$ Esteja atento para identificar barreiras educacionais, psicológicas e motivacionais do indivíduo e do grupo.

$\checkmark \quad$ Crie repertório amplo e que recorra à memória musical dos integrantes e da própria plateia para que todos possam se sentir motivados nas aulas e nos concertos.

$\checkmark$ Celebre cada nota, cada compasso e cada música conquistada.

$\checkmark$ Aprenda a ouvir, mesmo que a aula de música seja interrompida e precise se transformar em uma sala de terapia.

$\checkmark$ Diversifique $o$ acesso aos instrumentos musicais para que o aluno se identifique com o que melhor se adaptar. Não se adaptou a nenhum específico, convide-o a cantar.

$\checkmark \quad$ Não permita comparações ou disputas internas. A coletividade é fundamental. Todos ganham; todos perdem. A comunhão é fundamental para a autoestima e a conquista da cidadania.

A missão da prática de motivação por meio da performance não tem fim, mas é gratificante ao coração e à inclusão musical e social.

\section{Referências}

CARDOSO, Francisco. Papel da motivação na aprendizagem de um instrumento. Revista da Associação Portuguesa de Educação Musical, v. 8, n. 11, 2007. Disponível em: https://www.researchgate.net/publication/235654679_Papel_da_Motivacao_na_ Aprendizagem_de_um_Instrumento. Acesso em: 20 jul. 2020.

FORTIN, Marie-Fabienne. O processo de investigação: da concepção à realização. 5 . ed. Loures: Lusociência, 2009.

FREIRE, Teresa; TAVARES, Dionísia. Influência da autoestima, da regulação emocional e do gênero no bem-estar subjetivo e psicológico de adolescentes. Rev. Psiq. Clín., v. 38, n. 5, p. 184-188, 2011. Disponível em: http://www.periodicos.usp.br/acp/article/ view/17338/19366. Acesso em: 10 nov. 2020.

HALLAM, Susan. Musical motivation: towards a model synthesising the research. Music Education Research, v. 4, n. 2, p. 225-244, 2002.

LIMA, Sonia Albano de. Performance \& Interpretação Musical: uma prática interdisciplinar. São Paulo: Musa, 2006.

LOPES, Eduardo. Investigação em interpretação musical: paradigmas e o conceito de narrativas múltiplas. In: ZURBACH, Christine; FERREIRA, José Alberto (coord.). Investigação em Artes - Perspectivas, EA. Évora: Universidade de Évora, 2014. p. 23-36. Disponível em: http://dspace.uevora.pt/rdpc/handle/10174/13952. Acesso em: 19 jun. 2016. 
LUZ, Marcelo Caires. Educação musical na maturidade. São Paulo: Som, 2008.

MILHANO, Sandrina. Motivações e percepções da participação num projeto de valorização do envelhecer através das artes e da música - um estudo exploratório. In: CANASTRA, F.; SANTOS, G. P.; LOPES, M. S. P. (org.). Animação cultural: descobrindo caminhos. Leiria: ESECS; NIDE; CIID; Instituto Politécnico de Leiria, 2012.

MILLER, Olga; OCKELFORD, Adam. Visual needs. The sen series. London: Continuum, 2005.

SACKS, Oliver. Alucinações musicais, relatos sobre a música e o cérebro. Trad. Laura Teixeira Motta. 2. ed. São Paulo: Companhia das Letras, 2007.

SCHLICHTING, Felipe Paupitz. Motivação para aprender no NEP - Núcleo de Excelência em Piano. Trabalho de Conclusão (Bacharelado em Música - Piano) Universidade do Estado de Santa Catarina, Florianópolis, 2016.

WILLEMS, Edgar. Solfejo Curso Elementar. Adaptação portuguesa de Raquel Marques Simões. São Paulo: Fermata do Brasil, 2009. 